\title{
Prostate carcinoma: correlation of histopathology with serum prostate specific antigen
}

\author{
Deepika Gurumurthy ${ }^{1}$, Rangaswamy Maggad², Sapna Patel $^{2}$ \\ ${ }^{1}$ Department of Pathology, Apollo BGS, Mysore, India \\ ${ }^{2}$ Department of Pathology, JSS Medical College and Hospital, Mysore, India
}

Email address:

drdeepi_16@yahoo.com (D. Gurumurthy), rangaswamymaggad@gmail.com (R. Maggad), sapnaharish@gmail.com (S. Patel)

\section{To cite this article:}

Deepika Gurumurthy, Rangaswamy Maggad, Sapna Patel. Prostate Carcinoma: Correlation of Histopathology with Serum Prostate Specific Antigen. International Journal of Science, Technology and Society. Special Issue: Latest Different Concepts of Gynaecology.

Vol. 4, No. 4-1, 2015, pp. 1-5. doi: 10.11648/j.sjcm.s.2015040401.11

\begin{abstract}
Prostate Specific Antigen (PSA) is the first line test in screening of prostate cancer. The increase in PSA depends on differentiation of tumour cells. Gleason grading is one of the most powerful predictors of biological behaviour and influential factors used to determine treatment. PSA, when combined with Gleason score and clinical stage, improves the prediction of pathological stage for prostate carcinoma. Aims of this study were to study the histopathological features and Gleason grading in Prostatic Carcinoma and to correlate pretreatment PSA levels with Gleason grade. The study was undertaken in a tertiary care hospital over a period of two years.Fifty one cases of prostatic carcinoma were studied. Grading done by Gleason grading system, was correlated with serum PSA levels. Software statistical package for social sciences (SPSS), version 16 was used. P value $<0.05$ was considered significant. Patients were aged predominantly between 60 to 70 yrs. Majority (66.7\%) had poorly differentiated adenocarcinoma. $84.3 \%$ had high values of PSA (>10ng/ml). 5.9 \% had PSA value in normal range $(<4 \mathrm{ng} / \mathrm{ml})$. Though there was a comparative increase in PSA level with increase in Gleason grade, it was not statistically significant ( $p$ ' value $=0.75$ ). To conclude, a proportion of tumours with Gleason score 8-10 are so poorly differentiated that they produce relatively little PSA. Refinement in estimation and interpretation of PSA values may be considered to improve the sensitivity and specificity of PSA. Gleason grading is a better predictor of biological behaviour of prostate cancer.
\end{abstract}

Keywords: Gleason Grade, Prostate Cancer, PSA

\section{Introduction}

Prostate cancer is the most common cancer of men in USA and $10^{\text {th }}$ common malignancy in India ${ }^{[1],[2]}$. Patients don't experience symptoms during early stage and are unlikely to seek medical help until the disease has progressed. Hence, screening programmes aimed at early detection have been introduced.

PSA is the most useful tumour marker in diagnosis and first line test in screening ${ }^{[3],[4]}$. The increase in serum PSA depends on differentiation of tumour cells. Gleason grading is one of the most powerful predictors of biological behaviour and influential factors used to determine treatment. PSA, when combined with Gleason score and clinical stage, improves the prediction of pathological stage for prostate carcinoma $^{[5]}$.

We analysed the histolopathological features and Gleason grading in prostate carcinoma and correlated with pretreatment PSA.

\section{Subjects and Methods}

The present study was undertaken in a tertiary care hospital and 51 cases were studied over a period of 2 years (April 2011 to April 2013). All cases of prostatic biopsies, transurethral resection of prostate (TURP) specimens and radical prostatectomy specimens with or without clinical suspicion of malignancy which were proven as prostatic carcinoma on histopathological study and where serum PSA levels were available were included in the study. Biopsies with inadequate material and non malignant lesions were excluded. 
The specimens were fixed immediately in $10 \%$ formalin for 24 hours. Later they were processed routinely for paraffin sectioning and stained by Haematoxylin and Eosin stain. The slides prepared were analyzed and grading of prostate carcinoma was done by Gleason system.

Adenocarcinoma was assigned one of the four grades:

Grade 1 (score 2-4): Well differentiated

Grade 2 (score 5-6): Moderately differentiated

Grade 3 (score 7): Moderately - Poorly differentiated

Grade 4 (score 8-10): Poorly differentiated

The pre-treatment serum PSA levels were measured by Chemiluminiscence Immunoassay technique using Siemens Advia Centaur ${ }^{\circledR}$ CP Immunoassay system. S.PSA level $<04$ $\mathrm{ng} / \mathrm{ml}$ was considered normal. Gleason score was then correlated with serum PSA levels.

Ethical clearance was obtained from ethical committee. Statistical analyses were performed using the software SPSS, version 16. Oneway anova, Chi square test and Pearson's correlation coefficient was applied. $\mathrm{P}$ value $<0.05$ was considered significant.

\section{Results}

Patients presented predominantly with complaints of lower urinary tract symptoms (LUTS). Other complaints included acute urinary retention, backache, weakness of bilateral lower limbs, swelling of legs, hematuria and bleeding per rectum.

Patients were aged predominantly between $60-70$ yrs. The mean age at diagnosis in this study was $68 \mathrm{yrs}$. Youngest patient was 44yrs and oldest patient was 90 years.

All the cases displayed features of acinar adenocarcinoma. The various patterns observed include glands(Fig 1), cords(Fig 2), cribriform, sheets (Fig 3), hypernephroid and comedonecrosis(Fig 4). The most common was glandular pattern $(78.8 \%)$, followed by cords $(60.8 \%)$. Three cases $(5.9 \%)$ were associated with high grade prostatic intraepithelial neoplasia (HGPIN). In our study, majority $(66.7 \%)$ had poorly differentiated adenocarcinoma followed by moderately-poorly differentiated $(27.5 \%)$. Only $2 \%$ of the cases were well differentiated. [Graph 1]

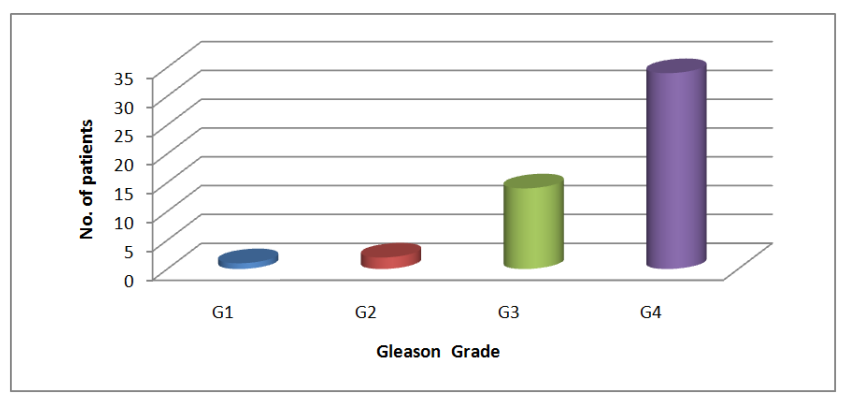

Graph 1. Distribution of Gleason grade

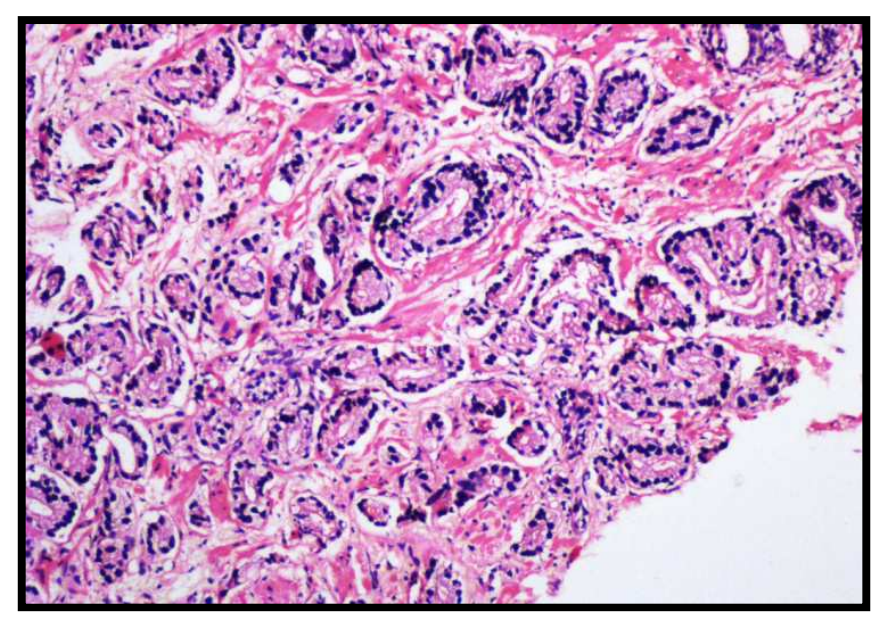

Figure 1. Tumor cells arranged in irregular small to medium sized glands with intervening stroma-Gleason score 3. ( $H \& E$, x10)

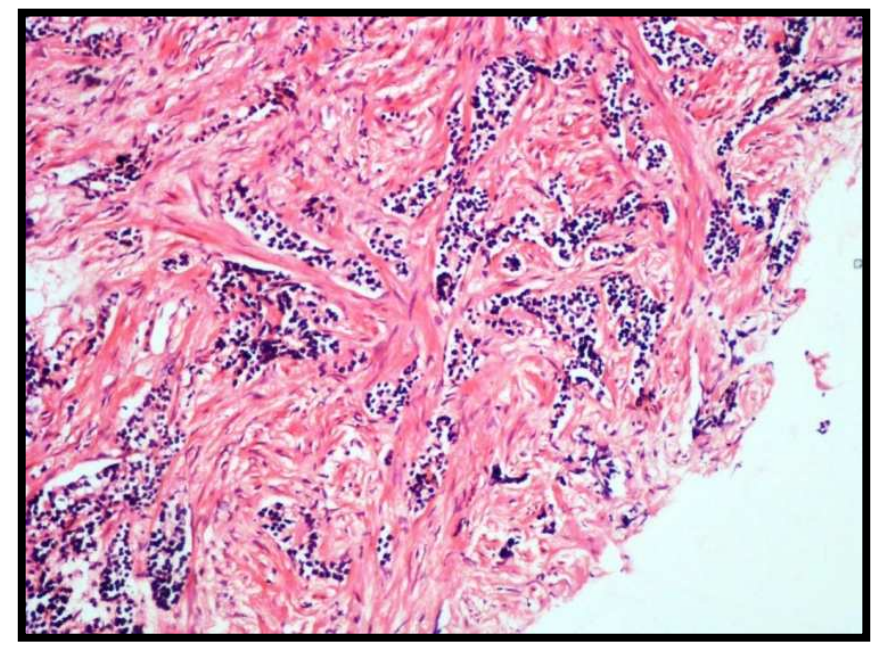

Figure 2. Tumor cells arranged predominantly in infiltrating cords- Gleason score 4. (H\&E,x100)

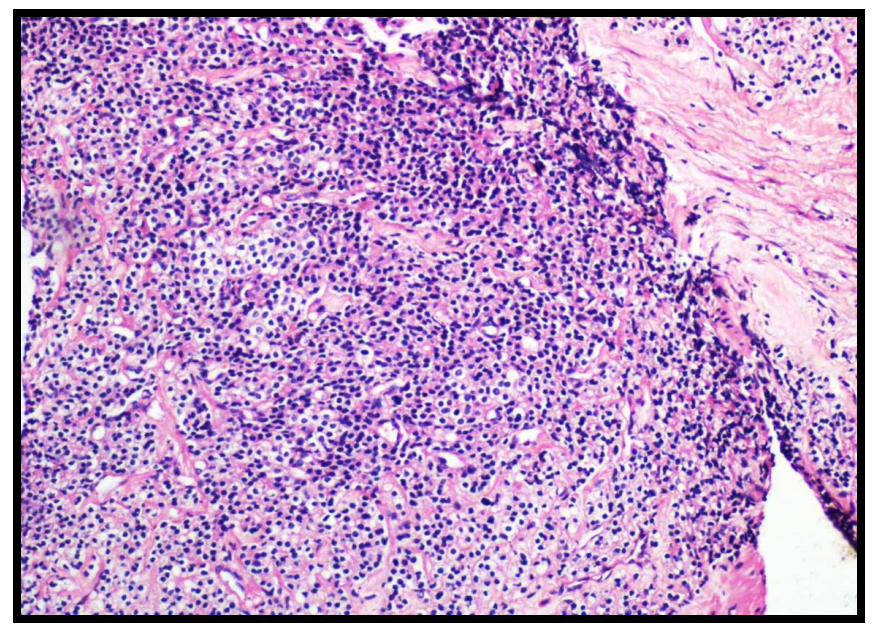

Figure 3. Tumor cells arranged predominantly in sheets- Gleason score 5. (H\&E, x100) 


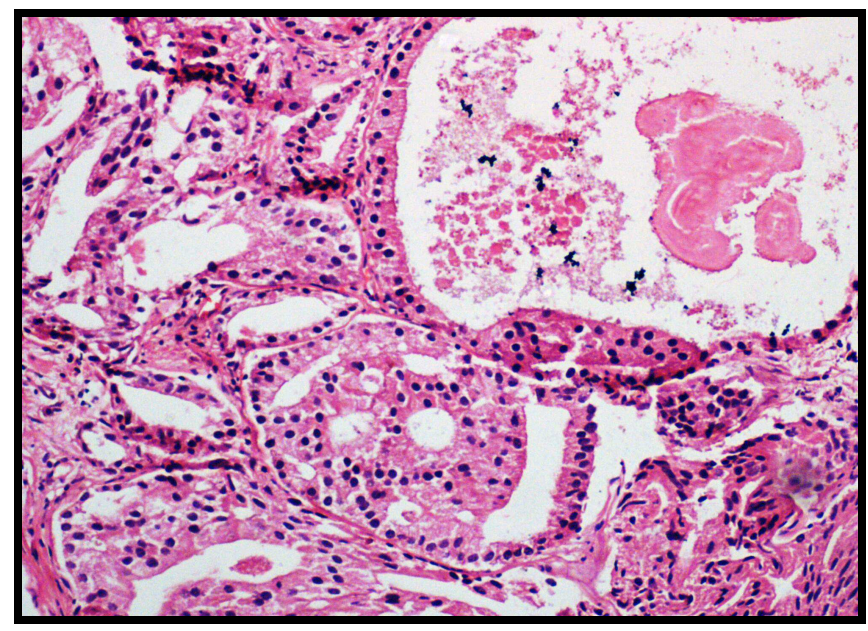

Figure 4. Tumor cells arranged in Cribriform pattern with ComedonecrosisGleason score 5. (H\&E, x200)

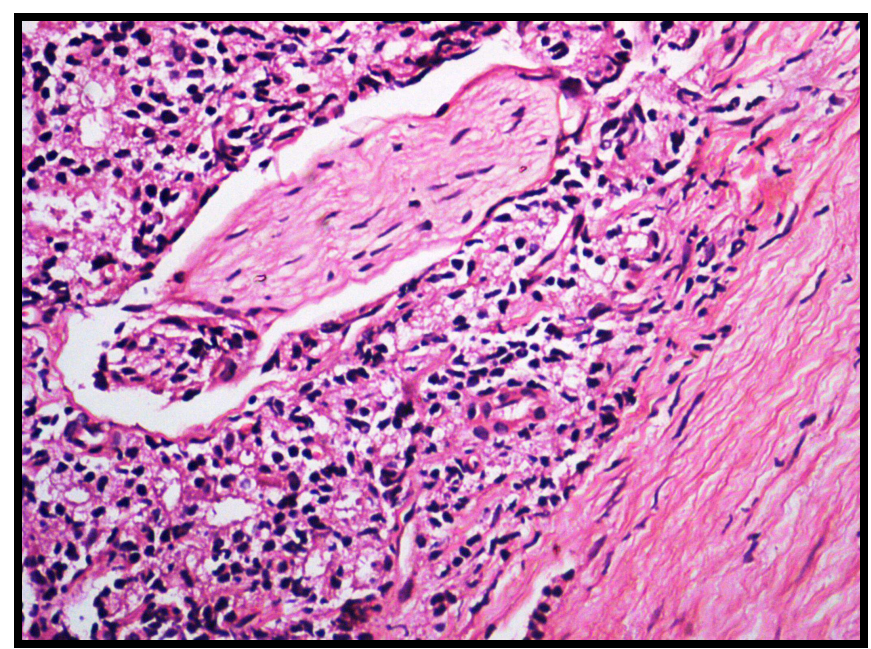

Figure 5. Perineural invasion by tumor cells. (H\&E, $x 400)$

Out of 12 cases, where we received both biopsy and TURP specimens, 5 cases underwent up gradation of Gleason score. PNI was seen in $52.9 \%$ of the cases (Fig 5).

Out of 51 cases, $6(11.8 \%)$ showed metastasis. All the 6 cases had bone metastases which were picked up by Positron Emission Tomography scan/Magnetic Resonance Imaging. $88.3 \%$ of these were Gleason grade 4 and $28.9 \%$ were Gleason grade 3. Perineural invasion was seen in $83.3 \%$ of these cases. Significant elevation of S.PSA levels $(>20 \mathrm{ng} / \mathrm{ml})$ were seen in $83.3 \%$ of these patients whereas $16.7 \%$ of the patients had PSA level within the normal range.

S.PSA values ranged widely from $1 \mathrm{ng} / \mathrm{ml}-415.4 \mathrm{ng} / \mathrm{ml}$ with a mean value of $55.11 \mathrm{ng} / \mathrm{ml}$. $84.3 \%$ of patients had high values of PSA $(>10 \mathrm{ng} / \mathrm{ml}) .5 .9 \%$ of the patients had PSA value in normal range $(<4 \mathrm{ng} / \mathrm{ml})$ and all the three cases had Gleason grade of 4. [Table 1] The age of the patient when correlated with S.PSA value in present study showed no significant rise in PSA value with age.

The mean value of S.PSA in grade 1 adenocarcinoma was $8 \mathrm{ng} / \mathrm{ml}$, in grade 2 was $42.5 \mathrm{ng} / \mathrm{ml}$, in Grade 3 was $44.1 \mathrm{ng} / \mathrm{ml}$ and in Grade 4 was $61.8 \mathrm{ng} / \mathrm{ml}$. The highest PSA level was in Gleason score of 8-10. Though there was a comparative increase in PSA level with increase in Gleason grade, it was not statistically significant ('p' value $=0.75$ ). [Table 2]

Table 1. Distribution of Pre treatment PSA

\begin{tabular}{lll}
\hline S.PSA $(\mathbf{n g} / \mathbf{m l})$ & Frequency & Percentage $(\%)$ \\
\hline $1-2.5$ & 3 & 5.9 \\
$2.6-10$ & 5 & 9.8 \\
$10.1-19.9$ & 6 & 11.8 \\
$>20$ & 37 & 72.5 \\
\hline
\end{tabular}

Table 2. Correlation between Gleason grade and pre treatment PSA levels

\begin{tabular}{lllll}
\hline \multirow{2}{*}{$\begin{array}{l}\text { Gleason } \\
\text { Grade }\end{array}$} & $\begin{array}{l}\text { No. of } \\
\text { Patients }\end{array}$ & PSA $(\mathbf{n g} / \mathbf{m l})$ & & \\
\cline { 3 - 5 } & 1 & 8 & 8 & 8 \\
\hline 1 & 2 & 30 & 55 & 42.5 \\
2 & 14 & 8 & 100 & 44.1 \\
3 & 34 & 1 & 415.4 & 61.7 \\
\hline
\end{tabular}

\section{Discussion}

Patients were aged predominantly between $60-70$ yrs. The mean age at diagnosis in this study was $68 \mathrm{yrs}$ and youngest patient was 44yrs. This is comparable with studies done by Mwakyoma HA et al, Jackson LA et al and Okolo $\mathrm{CA}$ et $\mathrm{al}^{[6],[7],[8]}$. In our study, there were four patients younger than 50 yrs who had prostate cancer. Studies by Jackson et al and Bunker et al showed three and nine patients who were below $50 \mathrm{yrs}$ respectively ${ }^{[7]}$. These findings confirm that prostate cancer is a disease of elderly men, although young men are not excluded.

All the cases displayed features of adenocarcinoma. This is in very close agreement with studies done by Mwakyoma HA et al (99.1\%), Jackson LA et al (100\%) and Thompson IM et $\mathrm{al}^{[6],[7]}$.

In our study, majority $(66.7 \%)$ had poorly differentiated adenocarcinoma followed by moderately to poorly differentiated $(27.5 \%)$. Only $2 \%$ of the cases were well differentiated. This is similar to that reported by Catalona WJ et al and Shirley SE et $\mathrm{al}^{[6],[19]}$. On the contrary, Jackson LA et al (69.68\%), Mwakyoma HA et al (61.1\%), Zivkovic S et al (52.5\%) reported, moderately differentiated adenocarcinoma (Gleason score 5-7) to be the predominant type ${ }^{[6],[7],[10]}$. Comparing our findings with those of others, the histological findings indicated that their patients had less aggressive disease than patients in our region. Our findings also reflect the relatively late clinical presentation of the patients.

Possible contributing factors for the above difference are:

- Genetic, environmental, racial and dietary factors ${ }^{[9]}$.

- Inter-observer variability in Gleason scoring ${ }^{[1]}$.

- Few authors have considered Gleason score 7 to be of moderately differentiated grade. On the other hand, we have grouped it in a separate category of moderatepoorly differentiated grade (as per World Health Organization). 
Out of the 12 cases where we received both biopsy and TURP specimens, 4 cases underwent up gradation of Gleason score. According to Corcoran NM et al, patients experiencing an upgrade in their Gleason score between biopsy and final specimen exhibit significantly more aggressive pathological features than corresponding concordant tumours, and a higher risk of biochemical recurrence post radical prostatectomy $^{[12]}$.

Three cases $(5.9 \%)$ were associated with high grade prostatic intraepithelial neoplasia (HGPIN). This is comparable to a study by Shirley SE et al (4.71\%). But studies by Horninger $\mathrm{W}$ et al $(61.4 \%)$ and Jackson LA et al $(18.2 \%)$ indicate much higher rates ${ }^{[7],[13]}$.

The incidence of HGPIN is relatively low in our study because most of the specimens were needle biopsies and TURP, which don't have enough material compared to radical prostatectomy studied in other studies. Many studies have shown that HGPIN is the major precursor of prostate cancer. HGPIN may evolve into an invasive cancer, a process that can take more than ten years to develop or remain unchanged $^{[14]}$.

Perineural invasion was seen in $52.9 \%$ of our cases. In a study by Shirley SE et al, $33.3 \%$ of the cases showed PNI ${ }^{[9]}$. Perineural invasion is an established risk factor in other malignancies and a recognized mechanism whereby cancer cells spread beyond the prostate by using the rich innervations of the posterior aspect of the prostate. However, existing publications on the significance of perineural invasion are contradictory. Studies by Freedland SJ et al and Ravery $\mathrm{V}$ et al found that it was not an independent prognostic factor. On the other hand, D'Amico AV et al, Rubin MA et al and Quinn DI et al reported that it was independently prognostic ${ }^{[15]}$. Despite multiple articles involving thousands of patients, the question of why there is still uncertainty about the prognostic value of perineural invasion has not been addressed.

Out of 51 cases, six $(11.8 \%)$ showed bone metastasis. Not all of the patients had undergone imaging studies, and therefore the prevalence of occult spread may have been higher than reflected by this value. Patients presented mainly with backache and weakness of lower limbs which may be due to pathologic fractures secondary to metastasis of prostate carcinoma to vertebra. $88.3 \%$ of these were Gleason grade 4 and $28.9 \%$ were Gleason grade 3 . Perineural invasion was seen in $83.3 \%$ of these cases. Significant elevation of S.PSA levels $(>20 \mathrm{ng} / \mathrm{ml})$ were seen in $83.3 \%$ of the patients. But one of the patients had PSA level within the normal range and a Gleason score of 5+5.In a study done by Shirley $\mathrm{SE}$ et al, $7 \%$ of the cases showed metastasis ${ }^{[9]}$. Most common sites of metastatic spread of prostatic carcinoma are the skeletal system and lymph nodes. Bone metastases are characteristically osteoblastic. Lumbar spine, sacrum, and pelvis are the most common locations, as a result of tumour spread via Batson's vertebral venous system. The diagnosis of bony metastasis secondary to prostate cancer significantly alters patient treatment. According to Abdellatif et al, Chybowski et al and Rhoden et al, the incidence of positive bone scans in patients with PSA less than $20 \mathrm{ng} / \mathrm{ml}$ is low. Thus, staging bone scans can be avoided in patients with PSA less than $20 \mathrm{ng} / \mathrm{ml}$ resulting in large economic savings. On the other hand, according to few studies done in Japan, the incidence of positive bone scan in patient group with low PSA levels was much higher than that in other studies performed in Western countries. This raises the suspicion that the behaviour of carcinoma prostate is different in Asian population compared with Caucasians, and PSA might not be a good indicator for predicting bone scintigraphy results in some ethnic group ${ }^{[16]}$.

S.PSA values ranged widely from $1 \mathrm{ng} / \mathrm{ml}-415.4 \mathrm{ng} / \mathrm{ml}$ with a mean value of $55.11 \mathrm{ng} / \mathrm{ml} .84 .3 \%$ of patients had high values of PSA $(>10 \mathrm{ng} / \mathrm{ml}) .5 .9 \%$ (three cases) of our patients had PSA value in normal range $(<4 \mathrm{ng} / \mathrm{ml})$ and all the three cases had Gleason score of 8-10.

In a study of 354 patients with carcinoma prostate (Gleason score 8-10) by McGuire BB et al, 17.5\% had PSA level $<4 \mathrm{ng} / \mathrm{ml}^{[17]}$. In a similar study by Thompson IM et al, $15.2 \%$ had PSA $<4 \mathrm{ng} / \mathrm{ml}$, out of which $14.9 \%$ had a Gleason score of 7 or higher ${ }^{[6]}$. About $5-10 \%$ of carcinomas produce little PSA. It is thought that these cancers are so poorly differentiated that the epithelial cells lose expression of a PSA encoding gene ${ }^{[18]}$. Thus, a growing tumour does not substantially increase serum PSA levels. In clinical practice, prostate biopsy is less likely performed for patients with low PSA levels. This could result in these tumours being diagnosed at a later stage than tumours producing more PSA. Also, patients with high grade, low PSA tumours have poorer prognosis than those of higher PSA levels ${ }^{[17]}$.

The mean value of S.PSA in Grade 1 Adenocarcinoma was $8 \mathrm{ng} / \mathrm{ml}$, in Grade 2 was $42.5 \mathrm{ng} / \mathrm{ml}$, in Grade 3 was $44.1 \mathrm{ng} / \mathrm{ml}$ and in Grade 4 was $61.8 \mathrm{ng} / \mathrm{ml}$. The highest PSA level was in Gleason score of 8-10. Though there was a comparative increase in PSA level with increase in Gleason grade, it was not statistically significant (' $p$ ' value $=0.75$ ). The results of various studies on correlation between Gleason grade and pre treatment PSA levels are conflicting. Some studies have reported positive correlation between the two ${ }^{[6],[7],[8],[10],[19]}$. According to them, prostate cancer cells produce more PSA than normal cells and hence poorly differentiated cancer cells secrete and release greater amounts of PSA than the well differentiated ones ${ }^{[19]}$. On the contrary, few studies have indicated inverse correlation ${ }^{[16],[20]}$. According to them, PSA production decreases with increasing histological grade ${ }^{[12]}$. The lack of correlation between Gleason score and PSA may be explained by decrease in production of antigen by higher grade lesions due to loss of expression of PSA encoding gene $^{[10],[17]}$.

\section{Conclusion}

Although evaluation of serum PSA can lead to diagnosis of clinically significant cancer at an early and potentially curable stage, not all prostate cancers are associated with an elevated serum PSA. Though there was a comparative increase in PSA level with increase in Gleason grade, it was 
not statistically significant ('p' value $=0.750$ ). Serum PSA level is influenced by differentiation of tumour. A proportion of tumours with Gleason score 8-10 are so poorly differentiated that they produce relatively little PSA. Hence, one should be cautious while interpreting PSA levels and has to correlate with digital rectal examination and prostate biopsy findings. Gleason grading is a better predictor of biological behaviour of prostate cancer. Refinement in estimation and interpretation of PSA values - free PSA levels, PSA density, PSA velocity may be considered to improve the sensitivity and specificity of PSA.

\section{References}

[1] http://www.cdc.gov/dcpc/data/men.htm. Accessed on 29/08/2013.

[2] Dubey D. The early use of prostate specific antigen for early detection of cancer prostate in India: Is it justified? Indian J Urol 2009;25:177-84.

[3] Karazanashvili G, Abrahamsson PA. Prostate specific antigen and human glandular kallikrein 2 in early detection of prostate cancer. J Urol 2003;169:445-57.

[4] Loeb S, Kettermann A, Carter HB, Ferrucci L, Metter EJ, Walsh PC. Does prostate growth confound PSA velocity? Data from the Baltimore longitudinal study of aging.J Urol 2008;180:1314-7.

[5] Partin AW, Oesterling JE. The clinical usefulness of prostate specific antigen: update 1994. J Urol 1994;152:1358-68.

[6] Mawakyoma H A, Mabandi J L. Prostate cancer; Correlation of Gleason's score and pretreatment prostate specific antigen in patients. Professional Med J 2010;17:235-40.

[7] Jackson LA, McGrowder DA, Lindo RA. Prostate specific antigen and Gleason score in men with prostate cancer at a private diagnostic radiology centre in western Jamaica. Asian Pacific J Cancer Prev 2012;13:1453-6.

[8] Okolo CA, Akinosun OM, Shittu OB, Olaopa OO, Okeke LI, Akang EU. Correlation of serum PSA and Gleason score in Nigerian men with Prostate Cancer. African journal of urology 2008; 14:15-22.

[9] Shirley SE, Escoffery CT, Sargeant LA, Tulloch T. Clinicopathological features of prostate cancer in Jamaican men. BJU International 2002; 89:390-5.
[10] Zivkovic S.Correlation between prostate specific antigen and histopathological difference of prostate carcinoma. ArchOncol 2004;12:148-51.

[11] Mulay K, Swain M, Jaiman S. Gleason's scoring of prostatic carcinoma: Impact of a web based tutorial on inter and intra observer variability. Indian J Pathol Microbiol 2008;51:22-5.

[12] Corcoran NM, Hong MKH, Casey RG. Upgrade in Gleason score between prostate biopsies and pathology following radical prostatectomy significantly impacts upon the risk of biochemical recurrence.BJU International 2010;108:E202-10.

[13] Horninger W, Volgger H, Rogatsch H, Strohmeyer D, Steiner $\mathrm{H}$, Hobisch A et al. Predictive value of total and percent free PSA in high grade prostatic intraepithelial lesion: Results of tyrol prostate specific antigen screening project. J Urol 2001;165:1143-5.

[14] Zynger DL, Yang X. High grade prostatic intraepithelial neoplasia of the prostate: The precursor lesion of Prostate Cancer.Int J Clin Exp Pathol 2009;2:327-38.

[15] Harnden P, Shelley MD, Clements H, Coles B, TyndaleBiscoe RS, Naylor B et al. The prognostic significance of perineural invasion in prostatic cancer biopsies: a systematic review. Cancer 2007;109:13-24.

[16] Abdellatif J, Hajji F, Elonodo JC, Ghadouane M, Ameur A, Abbar M. Update the Indicator Role of Serum PSA Level and Gleason Score of the Biopsy for the Presence of Bony Metastases: Bone Scan Findings in a North African Ethnic Group. J Cancer Sci Ther 2011;3:112-5.

[17] McGuire BB, Helfand BT, Loeb S, Hu Q, O’Brien D, Cooper P. Outcomes in patients with Gleason score 8-10 prostate cancer : relation to preoperative PSA level. BJU International 2011;109:1764-9.

[18] Weir EG, Partin AW, Epstein JI. Correlation of serum prostate specific antigen and quantitative immunohistochemistry. J Urol 2000;163:1739-42.

[19] Shih WJ, Gross K, Mitchell B, Collins J, Wierzbinski B, Maqoun $\mathrm{S}$ et al. Prostate adenocarcinoma using Gleason scores correlates with prostate specific antigen and prostate acid phosphatase measurements. J Natl Med Assoc 1992;84:1049-50.

[20] Schroder FH, Crvijsen VD, Koeter I, De Koning HJ,Vis AN, Hoedemaeker RF. Prostate cancer detection at low prostatespecific antigen. J Urol 2000;163:806-12. 